\title{
Artikkeli
}

\section{Televisio- ja tuotantoyhtiöiden haasteet ja mahdollisuudet monimediaalisessa ympäristössä}

\begin{abstract}
Television viihde- ja draamaohjelmat ovat muuttumassa monimediaalisiksi tuotannoiksi, jotka sisältävät itse ohjelmajaksojen lisäksi erilaisia ja eri alustoilla jaettavia sisältöjä. Tällaiset tuotannot tarjoavat televisioyhtiöille uudenlaisia mahdollisuuksia rakentaa katsojasuhdettaan, mutta ne myös haastavat monia televisiotuotannon käytäntöjä ja malleja. Tässä artikkelissa tarkastellaan, millaisia muutoksia monimediaalisuuden omaksuminen on tuonut suomalaiseen televisiotuotantoon. Artikkelissa analysoidaan suomalaisten ohjelmapäälliköiden ja televisiotuottajien kanssa tehtyjen haastattelujen pohjalta monimediaalisen televisiotuotannon käsitteitä ja käytäntöjä sekä televisiotuotantoa ja yleisradiotoimintaa liiketoimintana. Kaupallisille televisioyhtiöille monimediaalisten tuotantokäytäntöjen omaksuminen näyttää olevan luonteva askel sähköisen viestinnän kehityksessä, kun taas Ylen haasteena on löytää omat, julkisen palvelun arvoihin sopivat monimediaalisuuden muotonsa. Tuotantoyhtiöissä suurimmat haasteet puolestaan liittyvät uusien liiketoimintamallien kehittämiseen.
\end{abstract}

AVAINSANAT: televisiotutkimus, sisällöntuotanto, monimediaalisuus, yleisradiotoiminta, interaktiivisuus

$\mathrm{V}$ iimeisten kahden vuosikymmenen aikana television toimintaympäristö on muuttunut monin tavoin. Digitalisoiminen ja teknologinen konvergenssi ovat mahdollistaneet sisältöjen nopean ja helpon liikuteltavuuden viestimestä toiseen, mikä on avannut mediateollisuuden aloille aivan uudenlaisia tapoja tehdä yhteistyötä. Samalla yleisöä koskevat käsitykset ovat joutuneet uudelleenarvioinnin kohteeksi: välineestä ja alustalta toiseen vaeltavia, fragmentoituneita yleisöjä on toisaalta entistä vaikeampi tavoittaa, toisaalta vastaanottajilla on itse tuottamiensa sisältöjen ansiosta aiempaa näkyvämpi rooli mediateollisuudessa. Näiden muutosten takia tutkijat ennustivat jokunen vuosi sitten television korvautuvan internetissä levitettävillä sisällöillä ja henkilökohtaisilla päätelaitteilla. Tutkijoiden tunnelmia heijastelivat 
sellaiset kokoomateosten nimet kuin Television After TV - Essays on Medium in Transition (Spigel \& Olsson 2004) ja Television Studies After TV - Understanding Television in the Post-Broadcast Era (Turner \& Tay 2009). Viime vuodet ovat kuitenkin osoittaneet, että televisio puolustaa edelleen paikkaansa suurten kansallisten mediailmiöiden synnyttäjänä. Vaikka television kuolemasta ei enää puhuta, väline itse, sen sisällöt sekä niiden tuotanto ja vastaanotto ovat käyneet läpi merkittäviä muutoksia.

Televisiota ei tule enää ymmärtää autonomisena mediumina vaan yhteydessä muihin ruutuihin ja kulttuurisiin paikkoihin. Televisio-ohjelmia ei tuoteta eristyksissä muusta mediasta, vaan tuottajat olettavat, että ainakin osa yleisöstä sitoutuu sisältöihin erilaisilla alustoilla. (Roscoe 2004, 363; ks. myös Turner \& Tay 2009.) Monet mediayritykset ovatkin vastanneet teknologisen ja taloudellisen konvergenssin mukanaan tuomiin haasteisiin omaksumalla niin sisällön tuotannossa kuin jakelussakin monimediaalisen lähestymistavan (Doyle 2010, 1). Monimediaalisuutta voidaan pitää yhtenä sisällöllisen konvergenssin ilmenemismuotona. Konvergenssi ei siis viittaa ainoastaan digitaalisen teknologian mahdollistamaan sisältöjen liikkumiseen yli välinerajojen, vaan myös siihen kytkeytyviin tuotannollisiin, taloudellisiin, kulttuurisiin ja yhteiskunnallisiin muutoksiin (ks. esim. Jenkins 2006). Suomessakin television kotimaiset viihde- ja draamaohjelmat ovat laajentuneet monimediaalisiksi tuotannoiksi, joihin sisältyy televisiossa esitettävien ohjelmajaksojen lisäksi erilaisia muilla alustoilla tarjottavia sisältöjä ja sovelluksia. Usein näissä tuotannoissa tarjotaan myös yleisölle mahdollisuus osallistua jollakin tavalla ohjelman kulkuun. Monimediaalisuuden lisäksi monenlaiset yleisön osallistumista painottavat muutokset näkyvät kaikilla televisioteollisuuden tasoilla sisällöntuotannosta jakeluun (Doyle 2010, 3).

Tässä artikkelissa tarkastellaan, millaisia muutoksia monimediaalisuuden omaksuminen on tuonut suomalaiseen viihde- ja draamaohjelmien tuotantoon. Lähestyn aihetta kolmen keskeisen teeman kautta: 1) mitä monimediaalisuudella ymmärretään ja millaisin käsittein siitä puhutaan, 2) millaisia haasteita ja mahdollisuuksia monimediaalisuuteen sisältyy sekä 3) millaisia vaikutuksia monimediaalisten käytäntöjen omaksumisella on suomalaiseen televisiotoimialaan. Artikkelissa analysoidaan aineistovetoisesti monimediaalisen televisiotuotannon käsitteitä ja käytäntöjä sekä televisiotoimialan muutoksia. Lisäksi pohdin, millaisena 2010-luvun suomalainen televisio näyttäytyy julkisen palvelun televisioyhtiön, kaupallisten televisioyhtiöiden ja tuotantoyhtiöiden silmin.

Tutkimusta varten tehtiin 13 puolistrukturoitua haastattelua tammi-maaliskuussa 2014. Haastateltaviksi valittiin keskitason päälliköitä ja tuottajia neljältä kotimaiselta päätelevisiokanavalta sekä viihde- ja/tai draamaohjelmia tuottavien tuotantoyhtiöiden edustajia. Haastatteluihin osallistui siten kaksi ohjelmapäällikköä ja kaksi tuottajaa Ylen kanavilta TV1 ja TV2, ohjelmapäällikkö ja vastaava tuottaja MTV:Ita, kanavapäällikkö ja ohjelmapäällikkö Neloselta sekä viisi vastaavaa tuottajaa/toimitusjohtajaa itsenäisistä tuotantoyhtiöistä. Tutkimukseen valituissa tuotantoyhtiöissä tehdään sisältöjä sekä Ylelle että kaupallisille kanaville. Haastattelukysymykset koskivat monimediaalisiin televisiotuotantoihin liittyvää käsitteistöä sekä näiden tuotantojen haasteita ja mahdollisuuksia, televisiotyön muutoksia sekä yleisöjä ja interaktiivisuutta. 
Litteroidut haastattelut on analysoitu teemoittamalla: olen ryhmitellyt erilaisiin teemoihin liittyviä asioita ja muotoillut teemoille merkityssisältöjä suhteessa toisiin teemoihin ja tutkimuskirjallisuuteen (Moilanen \& Räihä 2001, 54). Edellä mainituista artikkelin keskeisistä teemoista kaksi ensimmäistä sisältyi tutkimuskysymyksiini, mutta kolmas, television lähetystoimintaa ja tuotantoa liiketoimintana käsittelevä teema nousi esiin haastatteluvastauksista. Kunkin teeman kohdalla julkisen palvelun televisiota, kaupallista televisiota ja tuotantoyhtiöitä on pääasiassa käsitelty omina lohkoinaan, jotta niiden välisiä eroja ja yhtäläisyyksiä on mahdollista vertailla. Analyysissa huomioni kiinnittyi ainoastaan haastattelupuheen sisältöön, ei sen muotoon. Aihetta on edelleen rajattu jättämällä osa haastatteluissa esiin nousseista teemoista tämän artikkelin ulkopuolelle. Tutkimus on osa Suomen Akatemian rahoittamaa Broadcasting in the Post-Broadcast Era: Technology, Policy, and Content Production -hanketta, jonka puitteissa vastaavia haastatteluja tehtiin myös Israelissa. Suomen ja Israelin välisen vertailevan tutkimuksen tuloksia on tähän mennessä julkaistu julkisen palvelun television osalta (Klein-Shagrir \& Keinonen 2014).

Televisiotuotannon muutoksia tarkastelevan tutkimukseni lähestymistapaa voidaan nimittää tuotannontutkimukseksi (production studies). Horace Newcomb ja Amanda Lotz (2002) ovat hahmotelleet tuotannontutkimukseen viisi analyysin tasoa, jotka kattavat fiktiotuotannon aina kansallisen ja kansainvälisen politiikan ja talouden tasolta yksittäisten toimijoiden tasolle asti. Esimerkkinä yhteen mediateollisuuden alaan keskittyvästä analyysista Newcomb ja Lotz mainitsevat klassikkotutkimuksen The Classical Hollywood Cinema (Bordwell ym. 1985), joka tarkastelee Hollywoodin elokuvateollisuuden rakentumista tietyn narratiivisen tyylin varaan. Bordwellin ja kumppaneiden tutkimuksen tapaan analyysini keskittyy yhden mediateollisuuden alan, tässä tapauksessa television viihde- ja draamatuotannon, (monimediaalisiin) käytäntöihin ja konteksteihin.

Vastaavan tason analyysia sisältyy myös liris Ruohon väitöskirjaan (2001), joka tarkastelee Yle TV2:n sarjadraaman tuotantoa, kritiikkiä ja tekijyyttä. Ruohon tutkimus ajoittui 1990-luvun puoliväliin, ajankohtaan, jossa Yleisradion ohjaajavetoinen sarjadraamatuotanto korvautui tuottajavetoisella mallilla. Nyt, lähes 20 vuotta myöhemmin, suomalainen televisiotuotanto elää jälleen murroskautta, kun konvergenssin mahdollistamat uudet tuotantostrategiat muuttavat media-ammattilaisten työnkuvaa ja ammatti-identiteettiä. Kuten Nele Simons, Alexander Dhoest ja Steven Malliet (2012, 28-29) toteavat, eri välineiden tuotantoprosessit olivat aiemmin erillisiä mutta liittyvät nyt yhä kiinteämmin toisiinsa, sillä erilaisilla alustoilla avautuvan narratiivisen kokonaisuuden luominen edellyttää tiivistä yhteistyötä eri tuotanto-osastojen välillä. Myös digitaaliseen mediaan olennaisena osana kuuluva interaktiivisuus muuttaa televisiotuotannon käytäntöjä. Uudet teknologiat ja sovellukset, kuten nettikamerat, älypuhelimet ja muut digitaaliset alustat, ovat hämärtäneet tuotannon ja kulutuksen, osallistumisen ja passiivisen katsojuuden välistä rajaa siinä määrin (Roig ym. 2009; Deuze 2008), että voidaan puhua "osallistumisen kulttuurista": yleisön jäsenet paitsi kuluttavat mediatuotteita myös osallistuvat niiden tekemiseen (Jenkins 2006). Tämän seurauksena media-ammattilaisten identiteetit rakentuvat vuorovaikutteisessa suh- 
teessa yleisöihin, jotka he näkevät sekä mediatekstien kuluttajina että kanssatuottajina (Deuze 2008).

Tutkimukseni konteksti rakentuukin sekä monimediaalisuutta että television interaktiivisuutta koskevista eurooppalaisista tutkimuksista. Erityisesti monimediaalisuutta Isossa-Britanniassa ja Norjassa käsittelevät tutkimukset tarjoavat reflektiopintaa omalle analyysilleni, sillä näiden maiden televisiojärjestelmissä on huomattavan paljon yhtäläisyyksiä julkisen palvelun televisiota ja kaupallista televisiota yhdistävän suomalaisen mallin kanssa. Tutkimukseni eroaa kuitenkin useimmista monimediaalisuutta koskevista analyyseista siten, että yhden tuotannon tai genren case-tutkimuksen sijaan tarkastelen kokonaista toimialaa. Lisäksi sisällytän tarkasteluuni sekä julkisen palvelun televisioyhtiön, kaupallisia yhtiöitä että tuotantoyhtiöitä. Koska suomalaisen televisiotuotannon muutoksia ei viime vuosina ole tutkimusjulkaisuissa juurikaan käsitelty, tarjoaa artikkelini myös yleiskuvan kotimaisen televisiotuotannon tilasta.

\section{Käsitteiden "viidakko"}

Monimediaalisten käytäntöjen omaksuminen osaksi televisiotuotantoa on parhaillaan käynnissä oleva prosessi. Vaikka sisältöjen tuottaminen erilaisille alustoille on jo "itsestään selvä" osa tuotantoyhtiöiden toimintaa (Pääkkönen 2014), ei alalle ole vielä muodostunut monimediaalisia tuotantoja koskevaa yhtenäistä käsitteistöä. Tämän takia haastateltavilta kysyttiin, millaisin termein he monimediaalisuudesta puhuvat. Akateemisessa tutkimuksessa televisiotoiminnan digitalisoimisen ja teknologisen konvergenssin synnyttämiin uusiin tuotantotapoihin viitataan pääasiassa monimediaalisuuden (multi-platform, crossmedia) ${ }^{1}$ ja transmediaalisuuden (transmedia) käsitteillä. Käsitteitä käytetään osin limittäin ja päällekkäin, mutta niiden avulla on myös mahdollista eritellä erilaisten alustojen ja sisältömuotojen välisiä suhteita. Monimediaalinen tuotanto viittaa tällöin sellaisiin viihteen tai draaman sisältöihin, joissa tarina kerrotaan useita erilaisia alustoja, kuten televisiota, internetiä ja mobiililaitteita hyväksi käyttäen. Yksinkertaisimmassa muodossaan monimediaalisuus tarkoittaa siis saman sisällön jakamista erilaisilla kanavilla tai laitteilla. (Simons, Dhoest \& Malliet 2012, 25.) Transmediaalinen tarinankerronta (transmedia storytelling) puolestaan viittaa tarinaan, joka avautuu useilla erilaisilla alustoilla siten, että jokainen mediateksti tuo kokonaisuuteen oman selvästi erottuvan ja arvokkaan lisänsä. Yksittäisten mediatekstien tai tuotteiden ymmärtäminen ei kuitenkaan edellytä kaikkien muiden osasten kuluttamista. (Jenkins 2003; Simons, Dhoest \& Malliet 2012, 25; Scolari 2009, 587.)

Tämä analyyttinen erottelu monimediaalisuuden ja transmediaalisuuden välillä ei kuitenkaan vastaa sitä tapaa, jolla käsitteitä käytetään televisio- ja tuotantoyhtiöissä. Huomattavasti kuvaavampi sen sijaan on kahden haastateltavani tarjoama luonnehdinta käsitteiden "viidakosta" (Paunio 2014; Saaranluoma 2014): erilaisia käsitteitä käytetään ristikkäin, päällekkäin ja limittäin. Esimerkiksi kaikki Ylen edustajat puhuivat sekä monimediaalisuudesta (tai monimediallisuudesta) että transmediasta, jos- 
kaan näiden kahden termin välisestä erosta ei ollut täyttä yksimielisyyttä. Monimediaalisuudella voidaan yksinkertaisimmillaan tarkoittaa saman sisällön jakamista eri välineissä (Mäki-Reinikka 2014), jolloin "katsoja saa tarvittavan informaation - - yhtä alustaa seuraamalla" (Väliahdet 2014). Transmediaalisuus taas hahmotetaan Ylessä joko 1) yleisön roolin tai 2) tuotannon ajallisen koordinoinnin kautta. Transmediaalinen tuotanto edellyttää yleisöltä useiden alustojen seuraamista samaan aikaan (Väliahdet 2014) tai osallistumista vuorovaikutukseen (Reijonen 2014). Tuotannon näkökulmasta se voi tarkoittaa erilaisten sisältöjen "reaaliaikais[ta]" jakelua eri alustoilla (Saaranluoma 2014), jolloin transmediaalinen tuotanto mahdollistaa suuremman käyttäjäkokemuksen ja on enemmän kuin osiensa summa (Mäki-Reinikka 2014).

Sekä MTV:ssa että Nelosella puhutaan monimediaalisuuden ohella 360-tuotannoista (Paunio 2014; Valtanen 2014; Suominen 2014). 360 asteen strategiassa sisältöjä koskeviin päätöksiin vaikuttaa ohjelman ideointivaiheesta lähtien se, millaiseksi ohjelman arvo ja sen eri jakelukanavissa synnyttämät tulot arvioidaan. Lähestymistapa moninkertaistaa ne jakelutiet, joiden kautta yleisö pääsee käsiksi sisältöön, ja pidentää siten ajanjaksoa, jonka sisällä se voi tuottaa voittoa. (Doyle 2012, 2, 7.) MTV:n kotimaisten ohjelmien päällikkö Matti Paunio vahvistaa, että jo ohjelmaa tilattaessa mietitään, millaisilla sisällöillä kannattaa lähteä liikkeelle (Paunio 2014). Nelosella, kuten Ylelläkin, lisämateriaalien ajatellaan laajentavan televisio-ohjelman ympärille syntyvää kokemusta (Mustelin 2014). Transmedia-käsitettä ei kaupallisissa televisioyhtiöissä mainittu lainkaan.

Laajin ilmiötä koskeva käsitteistö on käytössä tuotantoyhtiöillä, joissa puhutaan muun muassa sisällöntuotannosta eri alustoille, monimediaalisuudesta, crossmediasta, second screenistä, digitaalisesta mediasta, online-sisällöistä, 36o:sta sekä lineaarisesta ja non-lineaarisesta televisiosta (Hyytiä 2014; Vermilä 2014; Hietala 2014; Lehtinen 2014; Pääkkönen 2014). Kahden haastateltavani mukaan yleisin ja kuvaavin termi on tällä hetkellä juuri monimediaalisuus (Vermilä 2014; Hyytiä 2014), mutta hekin käyttävät käsitettä hieman eri merkityksessä. FremantleMedian Eerika Vermilä ymmärtää monimediaalisuuden ennen kaikkea tuotannon ominaisuutena: tuotantoyhtiön on pystyttävä tarjoamaan tv-kanavalle ohjelma, joka soveltuu television ohella internetissä sekä mobiilissa esitettäväksi ja johon saattaa liittyä lisämateriaalia, esimerkiksi nettisarjoja. Zodiak Finlandin Teea Hyytiä puolestaan näkee monimediaalisuuden nimenomaan mediakäytön kautta: vastaanottaja pystyy tarkastelemaan sisältöjä useasta eri mediasta samanaikaisesti, vaikka itse tuotantoprosessi ei olisikaan kovin monimediaalinen. Toisaalta kyse on Hyytiän mukaan "versioinnista": päämediaan räätälöidyn tuotteen lisäksi internetiin tai mobiilimediaan tehdään versioituja tuotteita, esimerkiksi lyhennelmiä tai teasereita. Shine Finlandin Tarja Pääkkönen (2014) määrittelee arkikäytössä olevan 360-ilmaisun tarkoittavan kaikkea mahdollista, mitä perinteisen television ympärille voidaan rakentaa. Aito Median Eero Hietala (2014) puolestaan erittelee ilmiöstä kaksi puolta: kyse voi olla Pääkkösenkin mainitsemasta olemassa olevien "broadcast-brändien" laajentamisesta tai täysin uusien sisältöjen luomisesta. Vaikka Hyytiän haastattelussa tulikin esille myös Ylessä painotettu yleisön rooli, ymmärretään monimediaalisuus tuotantoyhtiöissä pääosin televisioläh- 
töisesti ja käytännönläheisesti omien töiden kautta. Tämä voi osaltaan vaikuttaa siihen, että yhteisiä määritelmiä monimediaalisuudelle ei juurikaan löydy.

"Viidakkomaisuus" luonnehtii hyvin myös puhetta monimediaalisiin tuotantoihin usein liittyvästä interaktiivisuudesta. Haastattelukysymyksissä interaktiivisuuden mahdolliset merkitykset jätettiin avoimiksi. Haastateltavat käyttivätkin interaktiivisuuden rinnalla aktiivisuuden, osallistumisen ja vaikuttamisen käsitteitä viittaamaan niihin tapoihin, joilla vastaanottajat voivat olla vuorovaikutuksessa sekä mediatekstien, tuottajien että toistensa kanssa. Lähes kaikkien haastateltavien mielestä interaktiivisuus kuuluu olennaisena osana monimediaalisiin tuotantoihin, joskin sen toteuttamistapoja on harkittava ohjelma- ja lajityyppikohtaisesti. Kaupallisissa televisioyhtiöissä ja tuotantoyhtiöissä tavallisimmiksi interaktiivisuuden muodoiksi miellettiin äänestykset, pelit ja kilpailut sekä mahdollisuus saada oma mielipide julkaistuksi (Paunio 2014; Mustelin 2014; Suominen 2014; Hietala 2014; Pääkkönen 2014). Haastateltavat myös huomauttivat, että interaktiivisuus ei sinänsä ole mikään uusi ilmiö, sillä katsojien mielipidettä on aiemmin kysytty esimerkiksi postikortti- ja puhelinäänestyksissä (Mustelin 2014; Suominen 2014; ks. myös esim. Keinonen 2011, 148-149; Beyer ym. 2007; Enli 2012; 126).

Haastateltavieni mukaan monimediaalisuus on kuitenkin tarjonnut lineaariselle televisiolle uusia tapoja toteuttaa interaktiivisuutta (Suominen 2014; Hietala 2014). Shine Finlandin Tarja Pääkkösen (2014) mukana katsojien "aktiivisuus siirtyy nettiin, missä se on paljon notkeampaa ja helpompaa". Puhe ei siis itse asiassa olekaan television interaktiivisuudesta, vaan siitä, että yksisuuntaisen television rinnalle on tullut kaksisuuntaisen vuorovaikutuksen mahdollistavia viestimiä. Interaktiivisuudella voidaan myös tarkoittaa mahdollisuutta jakaa katsomiskokemus muiden kanssa (Valtanen 2014) ja kerääntyä tietyn ilmiön ympärille esimerkiksi Spotifyssä, Facebookissa tai Twitterissä (Vermilä 2014). Tutkimuksessa on aiemmin esitetty, että monet televisioammattilaiset uskovat tämäntapaisen katsojien osallistumisen lisäävän yleisön lojaaliutta ja siten televisioyhtiöiden tuloja (Ross 2008).

Vaikka interaktiivisuus tunnistettiin monimediaalisuuteen kuuluvaksi piirteeksi, haastateltavat varoivat korostamasta liikaa sen merkitystä. Muutamat jopa kritisoivat ilmiötä ympäröivää hypeä luonnehtimalla interaktiivisuutta "liioitelluksi" (Mustelin 2014) ja "illuusioksi" (Hietala 2014). Tulkintani mukaan tämä kritiikki viittaa siihen, että televisiotuotantoihin liittyvä interaktiivisuus on itse asiassa usein para-interaktiivisuutta. Para-interaktiivisuus viittaa televisuaalisiin strategioihin, joiden tarkoituksena on simuloida interaktiivista katsomiskokemusta tuomalla joitakin interaktiivisen vuorovaikutuksen elementtejä television kontekstiin. Strategioiden avulla pyritään rakentamaan tasa-arvoisemmalta ja vastavuoroisemmalta näyttävää suhdetta television katsojien ja tuottajien välille. (Klein-Shagrir 2013.) Tulkintaani tukee se, että ajatus katsojien muuttumisesta kanssatuottajiksi ja ammattilaisten tekemien sisältöjen korvautumisesta käyttäjien tuottamilla sisällöillä (user-generated content, UGC) tyrmättiin niin MTV:ssä, Nelosella kuin tuotantoyhtiöissäkin (Paunio 2014; Valtanen 2014; Pääkkönen 2014; Suominen 2014, Hyytiä 2014). Esimerkiksi Nelosen Olli Suominen totesi, että "[t]arinankerronnassa mä luotan siihen tavallaan, että jos on Suomen paras 
tyyppi kertomassa sen tarinan niin siitä tulee parempi kuin että me kerrotaan se - tässä yhdessä ja funtsitaan miten tämä menisi" (Suominen 2014).

Ylessä interaktiivisuus kuuluu kahden haastateltavani mukaan ehdottomasti monimediaalisen tuotannon filosofiaan (Väliahdet 2014; Reijonen 2014). Kaikista Ylessä tehdyistä haastatteluista välittyi kuitenkin ajatus siitä, että interaktiivisuus ymmärretään julkisen palvelun yhtiössä hieman toisin kuin kaupallisilla kanavilla. Ylessä interaktiivisuus ei ensisijaisesti tarkoita äänestysmahdollisuuksien tarjoamista katsojille (Saaranluoma 2014), vaan tavoitteena on aktivoida katsojia tavoilla, jotka eivät televisiossa ole mahdollisia (Väliahdet 2014). Yle pyrkii edistämään vuorovaikutusta yhtäältä katsojien ja tuotannon välillä ja toisaalta katsojien ja ympäröivän yhteiskunnan ja kulttuurin välillä. Tämä toteutuu esimerkiksi tarjoamalla yleisölle mahdollisuus osallistua suoraan lähetykseen "Twitter-feedin" avulla (Reijonen 2014), keskustella tuotantotiimin kanssa (Reijonen 2014) sekä ehdottaa tuotannolle ideoita ja aiheita, jotka huomioidaan ohjelman toteutuksessa (Mäki-Reinikka 2014; Saaranluoma 2014). Ylen ymmärrys interaktiivisuudesta tiivistyy hyvin TV2:n Riku Saaranluoman (2014) toteamuksessa: "tuotanto - - tulee lähelle [katsojaa], - - se on se juttu". Monimediaaliset tuotannot tarjoavat huomattavasti kehittyneempiä vuorovaikutuksen muotoja kuin esimerkiksi tekstiviestipohjaiset televisio-ohjelmat, joissa katsojien vaikutus ohjelmatekstiin voi olla joko rajoittunutta (limited), osittaista (partial) tai hallitsevaa (dominant influence) (Beyer ym. 2007, 228-229) mutta jotka eivät tarjoa mahdollisuutta esimerkiksi tuotannon ja katsojien väliseen keskusteluun itse ohjelman ulkopuolella. Monimediaalisuus voi siis avata julkisen palvelun yhtiölle uudenlaisia, kaupallisen television käytännöistä poikkeavia mahdollisuuksia toteuttaa interaktiivisuutta.

Haastatteluissa tuli myös eksplisiittisesti esille se, että korostamalla tuotantojensa avoimuutta ja läpinäkyvyyttä sekä katsojille että kaupallisille kilpailijoille² Yle tarjoaa vastinetta Yle-veron maksajille (Reijonen 2014). Interaktiivisuuden avulla Yle pyrkii aktivoimaan katsojiaan kansalaisina tarjoamalla heille internet-sivuillaan lisätietoa, linkkejä kansalaisjärjestöjen sivuille ja tilaa katsojien omille tarinoille (Väliahdet 2014). Julkisen palvelun yhtiöiden nettiportaalit toimivatkin usein "tienristeyksinä", joissa moninaiset yleisöt ja käyttäjäryhmät kohtaavat laajasti erilaisia ajatuksia, palveluja ja yhteisöjä. Julkisen palvelun arvojen mukaisesti televisio- ja radio-ohjelmia taustoittavat nettisivut tekevät näkyväksi erilaisia yhteiskunnallisia teemoja poiketen siten huomattavasti kaupallisten televisioyhtiöiden markkinointiin valjastetuista nettisivuista (Debrett 2009, 816, 818).

Julkisen palvelun kontekstissa tapahtuvasta katsojien aktivoimisesta voidaan puhua myös sosiaalisena televisiona. Haastateltavani eivät tätä käsitettä käyttäneet, mutta Media \& Message -seminaarissa puhuneet Risto Kuulasmaa ja Riku Rantala esittelivät Ylen ohjelmistoon kuuluvan Docventures-tuotannon nimenomaan termillä "social television", jossa ideana on "katsojien kokoaminen yhteen fiksujen sisältöjen ääreen". ${ }^{3}$ Juontajan ja yleisön välistä suhdetta monimediaalisissa tv-tuotannoissa analysoinut Gunn Sara Enli (2012) esittää, että digitaalisten viestintäkanavien käyttöönotto muuttaa aiemman parasosiaalisen vuorovaikutuksen katsojien ja tuotannon välillä sosiaaliseksi televisioksi, jossa tuottajat ovat riippuvaisia katsojien palautteesta, viesteistä 
ja äänistä. Vaikka sosiaalisen television käsite ei siis sinällään viittaa muuhun kuin intensiiviseen tuotannon ja katsojien väliseen vuoropuheluun, tekevät yhteiskunnan suuntaan osoittavat konnotaatiot siitä erityisen sopivan kuvaamaan julkisen palvelun tuotantoja, joissa vuorovaikutus pyritään ulottamaan myös katsojan ja yhteiskunnan välille.

Yleisön osallistaminen on siis tärkeä strategia julkisen palvelun yhtiöille (ks. myös Enli 2008, 110), vaikka tavoitteet ovatkin erilaiset kuin kaupallisissa televisioyhtiöissä. Koska julkisen palvelun yhtiöiden odotetaan tarjoavan "julkisen palvelun osallistumista", uuden teknologian mahdollistamien palautemuotojen ei tulisi redusoitua pelkäksi mediakeskeiseksi osallistumiseksi, vaan innoittaa demokraattista osallistumista. Kuten Enli toteaa, julkisen palvelun yleisradioyhtiöt etsivät monimediaalisia ohjelmakonsepteja, jotka tukevat ennemmin julkisen palvelun periaatteita kuin mediakeskeistä osallistumista, mutta houkuttelevat myös suuria yleisöjä. (Enli 2008, 117.)

\section{Televisio monimediaalisten tuotantojen "veturina"}

Mitä monimediaalisuus sitten käytännössä tarkoittaa? Mitä nämä monet mediumit ovat? Televisioyhtiöiden käyttämät mediumit, alustat ja sovellukset ovat pääosin samoja riippumatta siitä, onko kyseessä julkisen palvelun yhtiö vai kaupallinen tvyhtiö. Molemmissa hyödynnetään yhtälailla televisiota, radiota ja internetiä teknisinä alustoina, lisäksi kaupallisilla televisioyhtiöillä on käytettävissään saman mediakonsernin iltapäivälehdet eli printtimedia. Monimediaalisuuden alkumuotona voidaan pitää saman sisällön jakamista eri alustoilla (Pääkkönen 2014; Mustelin 2014), mutta nyt tarjolla on hyvin monenmuotoista materiaalia. Televisioyhtiöiden suoratoisto- eli netti-tv-palveluissa, kuten Yle Areenassa, Ruutu.fi:ssä ja Katsomo.fi:ssä voidaan esittää sekä samaa että eri sisältöä kuin televisiokanavalla. Televisioyhtiöillä, kanavilla, ohjelmilla ja fiktiivisillä sekä todellisilla televisiopersoonilla on Facebook-, Twitter ja Instagram-tilejä sekä YouTube-kanavia. Näitä kaupallisia sovelluksia hyödyntävät sekä kaupalliset televisioyhtiöt että Yle. Lisäksi ohjelman tarinamaailmaa voidaan jatkaa blogissa tai mobiiliapplikaatiossa ja siihen voi liittyä radiossa ja printtimediassa julkaistavia sisältöjä. Ylessä myös tapahtumallisuus on tärkeä osa monimediaalisuutta (Reijonen 2014; Mäki-Reinikka 2014), ja erityisesti Yle Teemalla monimediaalisuus toteutuu juuri live-tapahtumien kautta (Väliahdet 2014). Esimerkiksi Eurovision laulukilpailun kaltaiset live-tapahtumat ovat näytelleet tärkeää roolia julkisen palvelun kanavien pyrkimyksessä rakentaa kansallisia yleisöjä, ja ne ovat edelleen tärkeitä rakennuspalikoita yleisradioyhtiöiden ja niiden yleisöjen välisessä suhteessa (Enli 2008, 115).

Haastatteluissa nousi alustoista ja mediumeista kysyttäessä kaksi selkeää alateemaa esille. Ensinnäkin seitsemän haastateltavaa 13:sta korosti television merkitystä keskeisenä mediumina (Väliahdet 2014; Mäki-Reinikka 2014; Reijonen 2014; Paunio 2014; Valtanen 2014; Suominen 2014; Hyytiä 2014). Esimerkiksi Ylessä monimediaali- 
set tuotannot rakentuvat television ympärille (Mäki-Reinikka 2014; Reijonen 2014). Yle TV1:n ohjelmapäällikkö Pentti Väliahdetin (2014) mukaan televisio tulee vielä monen vuoden ajan olemaan konseptin "veturi" ja "markkinointialusta", jonka kautta suuret yleisöt voivat löytää tuotannon muita sisältöjä. Saman näkemyksen jakavat myös kaupallisten televisioyhtiöiden edustajat: kaikki haastateltavani korostavat television asemaa massamediana, joka luo ilmiöitä (Paunio 2014; Valtanen 2014; Suominen 2014; Mustelin 2014). Myös tutkimuksessa on todettu, että internet-sisältöjen menestys riippuu televisiosta, joka kerää suuria yleisöjä ja herättää kiinnostuksen digitaalisiin ja interaktiivisiin toimintoihin (Ihlabæk, Syvertsen \& Ytreberg 2013, 13). Uskoa television voimaan voidaan selittää lisäksi sillä, että "TV-kanava maksaa sen sisällön" (Suominen 2014): kaupallisella televisiolla on käytössään toimiva liiketoimintamalli, jossa ohjelmasisällöt maksetaan mainosajan myynnillä ja ohjelmasponsoroinnilla. Nettisisältöjen osalta vastaavia liiketoimintamalleja ollaan vasta etsimässä. Television keskeistä asemaa tukee Göran Bolinin $(2011,16)$ mukaan myös se, että television ja digitaalisen median konvergenssia ovat viitoittaneet juuri etabloituneet televisio-organisaatiot. Tämä havainto pitää paikkansa myös Suomessa.

Toiseksi useat haastateltavani korostivat monimediaalisuuden yhteydessä sisältöjen merkitystä. Heidän mukaansa tuotannossa täytyy keskittyä kiinnostavan sisällön kehittämiseen teknologian sijaan (Mäki-Reinikka 2014; Paunio 2014; Valtanen 2014). Monimediaalisuus on nähtävä "sisällöllisenä mahdollisuutena" (Paunio 2014), ja vasta kun sisältö on kunnossa, voidaan luoda "monimediaaliset ratkaisut siihen ympärille" (Mustelin 2014). Pentti Väliahdet (2014) puolestaan määritteli Ylen "sisältötuotantotaloksi". Tulkitsen tämän paitsi teknologisen determinismin välttämiseksi myös Ylen haluksi erottautua kaupallisista televisioyhtiöistä, jotka ovat jatkuvasti vähentäneet in-house-tuotantojen osuutta ohjelmistoissaan. ${ }^{4}$ Sisältöihin keskittyminen nousi suomalaisissa haastatteluissa esille myös vertailtaessa niitä vastaaviin israelilaisiin haastatteluihin. Israelilaiset televisiopäälliköt ja tuottajat lähestyivät monimediaalisuutta enemmän teknologiaa painottavasta näkökulmasta (Keinonen \& Klein-Shagrir 2014).

Jos haastateltavat olivatkin huomattavan yksimielisiä television ja sisältöjen merkityksestä, ei yhteistä näkemystä löytynyt kysymykseen siitä, millaisiin ohjelmiin monimediaalisuus sopii. Osa haastateltavista totesi, ettei kaikista ohjelmista ole tarpeen tehdä monimediaalisia tuotantoja (Väliahdet 2014; Mäki-Reinikka 2014). Toisten mielestä live-showt ja -tapahtumat, kuten urheilu- ja musiikkitapahtumat, ovat ihanteellisia ohjelmia yleisön aktivointiin (Saaranluoma 2014; Valtanen 2014; Hietala 2014). Myös tunteita herättävillä genreillä, kuten draamalla, realityllä ja viihteellä, on mahdollisuus kasvaa monimediaalisiksi tuotannoiksi (Saaranluoma 2014; Mustelin 2014; Valtanen 2014; Vermilä 2014; Pääkkönen 2014). Moskito Televisionin Roope Lehtisen (2014) mukaan tuotantoyhtiöt eivät itse asiassa voi enää myydä viihde-, lifestyle- ja reality-tuotantoja pelkkinä tv-ohjelmina. Monimediaalisuuden suhde ohjelmagenreihin ei siis näytä määrittyvän sen mukaan, katsotaanko asiaa Ylen, kaupallisten tvyhtiöiden vai tuotantoyhtiöiden näkökulmasta. Toki Ylen täytyy huomioida myös ne (lähinnä vanhempia ikäluokkia edustavat) katsojat, jotka eivät kaipaa monimediaalisia 
sisältöjä, kun taas kaupalliset televisioyhtiöt tavoittelevat pääasiassa parasta kuluttajaryhmää eli 25-39-vuotiaita naisia. Yhtiöstä riippumatta tärkeintä on haastateltavien mukaan kuitenkin se, että ohjelman konsepti soveltuu eri alustoilla jaettavaksi (Reijonen 2014) tai kiinnostaa television ohella muita viestimiä (Suominen 2014).

\section{Monimediaalisuuden haasteet ja mahdollisuudet kaupallisissa tv-yhtiöissä ja tuotantoyhtiöissä}

Artikkelini toinen ja kolmas teema käsittelevät monimediaalisten tuotantojen haasteita ja mahdollisuuksia sekä televisiotoimialan muutoksia. Koska nämä teemat kytkeytyvät tiiviisti toisiinsa, tarkastelen niitä rinnakkain ensin kaupallisten televisioyhtiöiden ja tuotantoyhtiöiden ja sitten Yleisradion osalta.

Haastateltavia pyydettiin nimeämään sekä haasteita että mahdollisuuksia, mutta sen lisäksi muihin kysymyksiin osoitetuissa vastauksissa tuli esille seikkoja, jotka olen tulkinnut haasteiksi tai mahdollisuuksiksi. Viime vuosina televisiotoimiala on kohdannut monenlaisia muutoksia, jotka usein kietoutuvat erottamattomasti yhteen. Teea Hyytiä (2014) toteaa televisiotuotannon eläneen suuren murroksen aikaa viimeiset viisi vuotta osin monimediaalisuuden, osin heikentyneen taloustilanteen takia. Kaupallisissa televisioyhtiöissä ja tuotantoyhtiöissä monimediaalisuus nähdään tällä hetkellä jo oleellisena ja luonnollisena osana toimintaa (Mustelin 2014; Lehtinen 2014; Pääkkönen 2014; Hyytiä 2014; Vermilä 2014). Esimerkiksi MTV on ollut "sähköisessä mediassa aina ja sähköistä mediaa - - tämä verkkomaailmakin on" (Valtanen 2014). Ymmärrettävistä syistä toiminnan laajentaminen kaupallisesta televisiosta muille (kaupallisille) alustoille ei ole edellyttänyt yhtiöiltä samanlaista arvopohdintaa kuin Yleltä.

Kaupallisten televisioyhtiöiden motiivit monimediaalisten tuotantokäytäntöjen omaksumiselle juontavat yleensä juurensa pitkän tähtäimen voiton maksimointiin (Doyle 2010, 6). Monimediaalisuus tarjoaa televisioyhtiöille keinon pysyä relevanttina yleisöille ja mainostajille, joiden intressit ovat siirtyneet televisiosta online- ja mobiilimediaan. Olli Suomisen mukaan Nelonen on asettanut monimediaalisille tuotannoille kaksi tavoitetta. Ensinnäkin Ruutu.fi on mainosrahoitteinen palvelu, johon saadaan myytyä mainontaa sitä paremmin, mitä enemmän siellä on kävijöitä. Toiseksi klippien jakaminen sosiaalisessa mediassa tuo katsojia päälähetykselle. (Suominen 2014.) MTV:n Matti Paunion mukaan tavoitteena on "saada enemmän katsojia sisällöille", mutta lisäksi hän korostaa monimediaalisuuteen liittyvää "palvelufunktiota": pyrkimyksenä on tavoittaa ja palvella katsojia aiempaa paremmin sekä syventää katsojakokemusta (Paunio 2014). Myös Nelosen Elina Mustelinin mukaan "katsojat haluavat - olla osa yhteistä katselukokemusta" (Mustelin 2014). Mustelin puhuukin MTV:n Sari Valtasen (2014) tavoin "ilmiön kehittämisestä" ja "ylläpitämisestä", "ilmiöitymisestä" monimediaalisuuden tavoitteena.

Ilmiöiden rakentamisessa hyödynnetään usein ristiinmarkkinointia (cross-promotion), johon monimediaalisuus tarjoaa aiempaa paremmat mahdollisuudet erityisesti 
monialaisissa mediayhtiöissä. Olli Suomisen (2014) mukaan "me ei tehdä sitä niin, että me tilattaisiin sisältöä Ilta-Sanomien printtilehteen, mutta toki me yritetään tilata sisältöä, josta Ilta-Sanomien printtilehti kiinnostuu". Toimittajia kutsutaan suoriin lähetyksiin, "keitrataan" ja toivotaan "että ne saisivat ikään kuin näistä esiintyjistä irti sitten jotain muutakin kuin mikä näkyy - - ruudussa olemalla siellä paikalla ja haastattelemalla niitä" (Suominen 2014). Esimerkiksi Vain elämää -sarjan yhteydessä Nelonen on tehnyt "aika tiivistäkin yhteistyötä" Radio SuomiPopin kanssa (Suominen 2014). Tuotantojen rakentaminen monimediaalisiksi ilmiöiksi on televisioyhtiöille paitsi mahdollisuus myös haaste, sillä "ohjelmat pitää pystyä myymään mainostajille ideoina, joista ei vielä näe, miten suureksi ilmiö kasvaa" (Suominen 2014). Toinen monimediaalisuuden mukanaan tuoma haaste muuttaa konkreettisesti televisiotuottajien ja -päälliköiden työnkuvaa, kun eri viestimiin levittäytyvät projektit muuttuvat aiempaa työläämmiksi ja vaikeammin hallittaviksi (Valtanen 2014; Mustelin 2014).

Tärkein, koko kaupallista televisiotoimialaa koskettava haaste liittyy analyysini perusteella jo aiemmin mainittuihin liiketoimintamalleihin. Kuten Sari Valtanen (2014) toteaa, verkko on "maailma, jossa on totuttu saamaan kaikki ilmaiseksi". Internetissä vallitsevan vapaan saatavuuden kulttuurin takia erityisesti mainstreamsisällöistä on vaikea veloittaa käyttömaksua (Doyle 2010, 4). Tällä hetkellä kaupalliset televisioyhtiöt tilaavat tavallisesti tuotantoyhtiöiltä vain televisio-ohjelman ja tuottavat itse muun ohjelmiin liittyvän materiaalin internetiin ja sosiaaliseen mediaan (vrt. esim. Simons, Dhoest \& Malliet 2013, 34). Tämä johtuu lähinnä siitä, että lineaarisen television tuotantoaikataulu osuu harvoin yksiin digitaalisen tuotannon kanssa: digitaalinen tuotantoprosessi kestää usein pidempään ja jatkuu jopa televisioesityksen jälkeen pitäen yllä ohjelman ympärille rakentunutta yhteisöä ja keskustelua (Bennett \& Medrado 2013, 108). Televisioyhtiöiden on kuitenkin vaikea saada nettisisältöjen tuotantoa kannattavaksi, koska perinteiset televisiotuotannot ovat huomattavan kalliita ja raskaita verrattuna siihen, mikä internet-levitykseen tarkoitetun sisällön minuuttihinnan tulisi olla (Suominen 2014).

Televisioyhtiöiden kokemat muutokset heijastuvat luonnollisesti myös niille sisältöjä myyviin tuotantoyhtiöihin, sillä televisio-ohjelmien esitysoikeuksien hinnoittelu on sekin muuttunut dramaattisesti. Olli Suomisen mukaan tuotantoyhtiö saattoi aiemmin myydä ohjelman esitysoikeudet televisioyhtiölle jaksojen lukumäärän mukaan määräytyvällä hinnalla, mikä oikeutti televisioyhtiön esittämään kunkin jakson yhden kerran omalla kanavallaan ennen tallenteiden palauttamista tuotantoyhtiölle. Enää televisioyhtiöt eivät osta yksittäisiä esitysoikeuksia, vaan esimerkiksi 20 käyttökertaa. Tässä mallissa käyttökerta viittaa siihen, että ohjelmaa voidaan yhdellä käyttökerralla esittää rajattomasti viikon ajan, minkä jälkeen se on vielä 30 vuorokauden ajan katsottavissa suoratoistopalvelussa joko maksutta tai maksua vastaan. (Suominen 2014.) Kuten Suomisen esimerkki osoittaa, sisältöjen ja niiden esitysoikeuksien hinnoittelu on siirtynyt tuotantoyhtiöiden käsistä televisioyhtiöille. Tilanne on tuotantoyhtiöiden näkökulmasta haastava, ja kaikki viisi haastattelemaani tuotantoyhtiöiden edustajaa mainitsikin uusien liiketoimintamallien löytämisen suu- 
rimmaksi monimediaalisuuteen liittyväksi haasteeksi (Vermilä 2014; Lehtinen 2014; Hietala 2014; Pääkkönen 2014; Hyytiä 2014). Toisaalta Eero Hietala (2014) näkee, että monimediaalisuus tarjoaa tuotantoyhtiöille mahdollisuuden rakentaa itse uusia alustoja ja luoda niille liiketoimintamallit. Tämä toki edellyttää tuotantoyhtiöiden osaamisen laajentamista sisällöntuotannosta jakeluun.

\section{Yle monimediallisessa ympäristössä}

Monimediaalisuuteen liittyvät haasteet kytkeytyvät siis laajempaan televisiotoiminnan murrokseen, jossa kaupalliset televisioyhtiöt ja tuotantoyhtiöt joutuvat arvioimaan toimintaansa uudelleen.

Myös Ylessä tunnelmat ovat ristiriitaiset. Ylen genretuottajan Marja Mäki-Reinikan (2014) mukaan monimediaalisuus on jopa "vähän semmoinen pakko ottaa haltuun -asia jollain tavalla, muuten me rajataan itsemme aika marginaaliin". Pentti Väliahdet (2014) puolestaan toteaa, että "kehitys on yhdenmukainen ja - - se että hyväksytäänkö vai eikö hyväksytä on vähän naiivi ajatus". Nämä näkemykset heijastelevat ajatusta monimediaalisuudesta "suojautumiskeinona": Gillian Doylen mukaan monet suuret yleisradioyhtiöt näkevät monimediaalisuuden välttämättömänä strategiana, jonka avulla ne pyrkivät puolustamaan markkina-asemaansa aikana, jolloin yleisön ja mainostajien käyttäytyminen on muutoksessa (Doyle 2010, 6). Monimediaalisuuteen siirtyminen on siis toisaalta väistämätön muutos, johon on sopeuduttava, mutta toisaalta se avaa myös yleisradioyhtiöille uusia mahdollisuuksia. Ylen osalta haastatteluissa nousi esiin kaksi monimediaalisuuteen liittyvää tavoitetta. Ensimmäinen liittyy nuoriin yleisöihin, jotka ovat kasvaneet monikanavaisesssa ja monimediaisessa ympäristössä. Sosiaalisessa mediassa yhä enemmän aikaansa viettävien teini-ikäisten ja nuorten aikuisten tavoittaminen on yksi julkisen palvelun television suurimpia haasteita (van Dijck \& Poell 2014, 2). Monimediaalisten tuotantojen avulla Yle pyrkii tavoittamaan haastavimman kohderyhmänsä, alle 30-vuotiaat katsojat ja erityisesti alle 20-vuotiaat miehet (Väliahdet 2014; Mäki-Reinikka 2014; Reijonen 2014). Esimerkiksi Yle TV2:n monimediaalinen Uusi päivä -konsepti on jo saanut faneikseen 10-14-vuotiaita tyttöjä, jotka käyttävät aktiivisesti sosiaalista mediaa ja odottavat löytävänsä myös sieltä sarjaan liittyviä sisältöjä (Reijonen 2014).

Toinen tavoite on markkinoida Ylen sisältöjä erilaisten välineiden avulla siellä, missä yleisöt ovat (Saaranluoma 2014; Mäki-Reinikka 2014; Reijonen 2014). Facebookin, Twitterin ja Instragramin tapaisten kaupallisten sovellusten käyttäminen julkisin varoin tuotettujen sisältöjen markkinointiin ei kuitenkaan ole täysin ongelmatonta ja Yleisradiota onkin tästä kritisoitu. Esimerkiksi Media \& Message -seminaarissa MTV Median entinen ohjelmajohtaja Jorma Sairanen kertoi Ylen Facebookin ja Twitterin käytön jalkapallon MM-kisojen yhteydessä kesällä 2014 herättäneen närää. Ylen televisiopäällikkö Riitta Pihlajamäki vastasi paneelikeskustelussa Ylen tavoittelevan tavoittavuutta - siksi Facebookissa ja Twitterissä on oltava. ${ }^{5}$ Myös haastateltavani näkivät kaupallisten sovellusten käytön välttämättömyytenä, jonka suhdetta julki- 
sen palvelun arvoihin ei nähty tarpeelliseksi pohtia sen syvällisemmin. Yle pyrkii kuitenkin erottautumaan kaupallisesta mediasta sisäisellä ohjeistuksella, jonka mukaan kaiken, mitä julkaistaan sosiaalisessa mediassa, tulisi löytyä myös Ylen omilta riippumattomilta alustoilta (Reijonen 2014): "meillä se peruslogiikkahan talossa on se, että me ei talon ulkopuolisille alustoille - - tehdä eri materiaalia" (Saaranluoma 2014). Tämä periaate ei tosin Uuden päivän tuottajan Samu Reijosen mukaan aina toteudu, koska Ylen omille alustoille ei ole mahdollista laittaa kaikkea sitä materiaalia, mitä sosiaalisessa mediassa voi julkaista. Reijonen näkeekin Facebookin yhtenä työvälineenä muiden joukossa samaan tapaan kuin tietynmerkkiset kamerat ja tietokoneet. (Reijonen 2014.)

Aineistoni perusteella Ylen suhde sosiaaliseen mediaan näyttää heijastelevan Jose van Dijckin ja Thomas Poellin (2014) hahmottelemaa, 2000-luvun alkuvuosiin ajoittuvaa muutosta yleisradiotoiminnan ja sosiaalisen median suhteissa. Facebookin tapaiset yhteisöviestintäpalvelut ja YouTuben kaltaiset käyttäjien tuottamiin sisältöihin perustuvat palvelut syntyivät alun perin yksityisten henkilöiden pyrkimyksistä kehittää uudenlaista mediatilaa. Koska näillä sovelluksilla näytti olevan potentiaalia viestinnän demokratisoimisessa, myös julkisen palvelun yleisradioyhtiöiden oli oltava niissä mukana. Sovellukset muuttuivat kuitenkin nopeasti globaalien yritysten omistamiksi ja kaupallisesti hyödynnettävään dataan keskittyviksi alustoiksi. Tällä hetkellä sosiaalisen median logiikka vaikuttaa jo kaikkiin julkisen elämän ja kanssakäymisen muotoihin, myös yleisradiotoimintaan, mutta toisaalta niiden täydellinen välttäminen johtaisi nuorempien katsojasukupolvien varmaan menettämiseen. (van Dijck \& Poell 2014, 4.) Myös televisiomaksusta Yle-veroon siirtymisen koetaan kasvattaneen Yleen kohdistuvia tavoitettavuuden vaatimuksia: "kaikki maksaa meidän sisällöistä ja ne pitää olla jotenkin kaikkien saatavilla ja löydettävissä ja tavoitettavissa" (Mäki-Reinikka 2014). Ylen on siis toisaalta tavoitettava erilaiset yleisöryhmät, toisaalta asetettava sisältönsä kaikkien tavoitettaville.

Monimediallisen televisiotuotannon käytäntöihin liittyvät haasteet näyttävät analyysini pohjalta olevan Ylellä samantyyppisiä kuin kaupallisissa televisioyhtiöissä. Ohjelmistonsuunnittelu, projektinjohtaminen ja sisällöntuotanto edellyttävät monimediaalisessa ympäristössä uudenlaisia valmiuksia (Väliahdet 2014; Saaranluoma 2014; Mäki-Reinikka 2014; Reijonen 2014). Ohjelmapäälliköiden on harkittava, kuinka monta monimediaalista tuotantoa voi käynnistää samanaikaisesti ilman, että ne kilpailevat keskenään yleisöistä - ja millaisiin tuotantoihin monimediaalisuus ylipäätään sopii (Saaranluoma 2014). Myös taloudellisten resurssien niukkuus asettaa omat haasteensa Ylelle (Mäki-Reinikka 2014): koska sisältöjen tuottaminen useille alustoille maksaa enemmän kuin ohjelman tekeminen ainoastaan lineaariseen televisioon, on sisältöjä priorisoitava (Saaranluoma 2014). Tuottajilta puolestaan vaaditaan laaja-alaista osaamista, sillä esimerkiksi Uudessa päivässä työnkuva vaihtelee "autokuskista musiikkivideokuvaajaksi" (Reijonen 2014). Reijosen oman sukupolven tuottajista kaikki osaavat tehdä sisältöjä, esimerkiksi kuvata, ohjata tai leikata, mutta tehtävärajat ylittävää ymmärtämystä vaaditaan kaikilta muiltakin tuotantotiimin jäseniltä. Lisäksi Uudessa päivässä nettituottaja on ensimmäistä kertaa Ylessä sijoi- 
tettu osaksi tuotantotiimiä, jolloin muiden tiimin jäsenten on helpompi ymmärtää, mistä nettisisällöissä on kyse. Tällainen organisatorinen uudelleenjärjestely voi olla jopa onnistuneen monimediatuotannon edellytys. (Reijonen 2014.)

\section{Televisiotuotannon nykyisyys ja tulevaisuus}

Vastausten hajaantuminen useissa kysymyksissä havainnollistaa sitä epävarmuutta, joka edelleen ympäröi monimediaalisia tuotantoja. Vaikka lähes kaikkiin televisioohjelmiin liittyy muissa välineissä tai muilla alustoilla jaettavia sisältöjä, eivät monimediallisia tuotantoja koskevat käytännöt ja käsitteet ole vielä vakiintuneet. Sekä televisio- että tuotantoyhtiöt opettelevat, kokeilevat ja testaavat pyrkien löytämään omia tavoitteitaan parhaiten tukevat monimediaaliset käytännöt ja mallit. Kaupallisille televisioyhtiöille monimediaalisten tuotantokäytäntöjen omaksuminen on ollut suhteellisen luonteva askel sähköisen viestinnän kehityksessä, kun taas Yle näyttäisi lähinnä seuraavan katsojia uusille alustoille. Ylen haasteena onkin löytää omat, julkisen palvelun arvoihin sopivat monimediaalisuuden muotonsa. Tuotantoyhtiöissä suurimmat haasteet taas liittyvät uusien liiketoimintamallien kehittämiseen, sillä jakeluteiden moninkertaistuminen on pakottanut televisioyhtiöt arvioimaan uudelleen esitysoikeuksien hinnoitteluperusteita.

Kansainvälisesti tarkasteltuna monimediaalisten tuotantojen kehittäminen on Suomessa resursseihin nähden melko edistyksellistä. Suomea ja Norjaa on pidetty jopa monimediaalisten televisiotuotantojen edelläkävijöinä (Beyer ym. 2007, 215-216), mutta aivan näin optimistisesti eivät haastateltavani tilannetta nähneet. Ylen tuottajat arvioivat Yleisradion jääneen jonkin verran jälkeen monimediaalisten tuotantojen kehittämisessä verrattuna esimerkiksi Ruotsiin tai Tanskaan (Reijonen 2014; Mäki-Reinikka 2014). Ohjelmapäälliköistä Väliahdet (2014) korosti Ylen pyrkimystä "elää aallonharjalla tai vähän sen edelläkin", vaikka niukat (taloudelliset) resurssit rajoittavatkin tuotantojen innovatiivisuutta (Väliahdet 2014; Saaranluoma 2014). Myös kaupallisissa yhtiöissä suomalaisen televisiotuotannon nähtiin edustavan vähintään keskitasoa, ellei jopa alan kärkeä (Paunio 2014; Valtanen 2014; Mustelin 2014; Suominen 2014). Niukkojen resurssien ja pienen markkina-alueen katsottiin rajoittavan kokeilevuutta (Paunio 2014; Suominen 2014), mutta toisaalta kotimaiset innovaatiot, kuten Tellyo ja The Voice of Finlandiin kehitetty online-applikaatio sekä älypuhelinten ja laajakaistayhteyksien laaja peitto kohentavat Suomen asemaa kansainvälisessä vertailussa (Mustelin 2014; Valtanen 2014). Myös Matti Paunion (2014) mukaan "Suomessa ollaan tällä alalla erittäin hyviä saamaan tosi hienoja tuloksia pienillä resursseilla". Tuotantoyhtiöissä suomalaisen monimediaosaamisen arvioitiin edustavan hyvää keskitasoa (Hyytiä 2014; Vermilä 2014; Lehtinen 2014; Pääkkönen 2014). Ainoastaan Eero Hietala (2014) näkee monimediaalisuuden olevan Suomessa hyvin "alkeellisella tasolla", mikä johtuu siitä, että toimivaa liiketoimintamallia on vaikea hylätä.

Kotimaisen televisiotuotannon tulevaisuutta haastateltavat maalailivat kahden kiinnostavan vision avulla. Eero Hietalan mukaan tulevina vuosina ratkaisevaa on, 
kuka omistaa sisällöt, sillä moni televisiotuotannon väliporras, kuten mediatoimistot, tulee katoamaan alalta. Jos tuotantoyhtiöt voivat itse kontrolloida omia sisältöjään, niillä on mahdollisuus kehittää uusi, ikkunoinnin mahdollistava ansaintamalli. (Hietala 2014.) Ikkunointi eli windowing viittaa jakeluprosessin suunnitteluun sen mukaan, millaisia voittoja saadaan myymällä audiovisuaalista sisältöä erilaisten kanavien tai "ikkunoiden" kautta järjestämällä jakelujaksot mahdollisimman tuottoisaan järjestykseen (Doyle 2010, 3). Elokuvateollisuudessa ikkunoinnin avulla määritellään esimerkiksi elokuvien teatteriesitysten, DVD- tai BlueRay-julkaisujen ja televisioesitysten ajankohdat. Ikkunoinnin ansiosta myös tuotantoyhtiöt voisivat tulevaisuudessa myydä sisältöjensä esitysoikeuksia muillekin kuin televisioyhtiöille.

Olli Suominen puolestaan ennustaa sisältöjen jakautumista "kahden kerroksen tuotannoiksi": laadukkaiden prime-time-ohjelmien ohella tuotantoyhtiöt voivat jatkossa tehdä edullisempaa nettilevitykseen tarkoitettua materiaalia. Yksi tuotanto voisi tällöin sisältää vaikkapa kahdeksan tuntia prime-time-ohjelmaa ja 72 tuntia sen ympärille tehtyä muuta sisältöä. Muutos laajentaisi televisiotuotantojen skaalaa ja hämärtäisi genrerajoja, mutta ei poistaisi niitä kokonaan: "jos meille tulee nyt käsikirjoitettua realitya, niin sehän on vähän niin kuin tekisi draamaa mutta realityn hinnalla". Suomisen mukaan viitteitä "kahden kerroksen tuotannoista" on jo nähtävissä Sanoma Oy:ssä, joka omistaa sekä Nelosen että Ilta-Sanomien netti-tv-kanava IS-TV:n. (Suominen 2014.)

Kuten odottaa sopii, televisioammattilaiset korostavat mielellään television merkitystä monimediaalisten tuotantojen "veturina". Toki myös suosituimpien televisioohjelmien katsojaluvut tukevat ajatusta siitä, että televisio kykenee edelleen kokoamaan suuria kansallisia yleisöjä yhteisten sisältöjen äärelle. Elina Mustelin (2014) kuitenkin uskoo, että "ihan lähitulevaisuudessa" televisiotyöntekijöiden täytyy hylätä välinelähtöinen ajatus televisioyhtiöstä ja ryhtyä tekemään sisältöjä myös muihin viestimiin. Muutos edellyttää myös tutkimukselta metodologista uudistumista: television tuotantokäytäntöihin ja estetiikkaan keskittyvän tutkimuksen sijaan analyysin on kohdistuttava monimediaalisiin, eri alustoille levittäytyviin sisältöihin. Tällä hetkellä suurin tutkimuksellinen haaste aiheutuu muutoksen nopeudesta: jos koko televisioala käsitteistöä myöten on murroksessa, on siitä mahdotonta tutkimuksessakaan esittää yksiselitteisiä väitteitä. Ongelma korostuu tämän artikkelin kaltaisessa aineistolähtöisessä tutkimuksessa, jossa ameebamaista tutkimuskohdetta ei ole pyritty pakottamaan ennalta määrättyyn teoreettiseen muotiin. Vaikka vaarana on, että analyysi jää jossain määrin kuvailevaksi, se voi silti onnistua tallentamaan jotain olennaista tietystä muutoksen hetkestä, tässä tapauksessa vuoden 2014 alun tilanteesta. 


\section{Viitteet}

1 Englanninkielisten termien multi-platform ja crossmedia välille ei ole tutkimuksessa määritelty selkeää eroa, joten molemmat on suomennettu tässä monimediallisuudeksi. Multi-platform-termin suora käännös "monialustaisuus" korostaa liiaksi teknologisia alustoja, "multimedia"-sanalla taas on oma, vakiintunut ja jo vanhentunutkin merkityksensä.

$2 \quad$ Mm. Nelosen edustajia on käynyt tutustumassa Uuden päivän tuotantoon (Reijonen 2014).

3 Risto Kuulasmaa ja Riku Rantala: Docventures Social Television - Suomen suurin leffakerho, esitys Media \& Message -seminaarissa Naantalissa 7.-8.8.2014.

$4 \quad$ Ks. esim. http://www.taloussanomat.fi/media/2011/11/o2/helsingin-sanomat-ryhtyy-tuottamaannelosen-uutisia/201115978/135; http://www.kauppalehti.fi/etusivu/mtv3+45+minuuttia+loppuu, +huom enta+suomi+ulkoistetaan/201310541223 (linkit tarkistettu 24.10.2014). Riitta Pihlajamäki Media \& Message -seminaarin TV-johtajapaneelissa Naantalissa 7.-8.8.2014.

\section{Haastattelut}

Hietala, Eero, Aito Media, luova johtaja, haastattelu 12.2.2014 Helsingissä.

Hyytiä, Teea, Zodiak Finland, managing director, haastattelu 4.3.2014 Helsingissä.

Lehtinen, Roope, Moskito Television, toimitusjohtaja, haastattelu 12.2.2014 Helsingissä.

Mäki-Reinikka, Marja, Yle, viihteen genretuottaja, haastattelu 10.2.2014 Helsingissä.

Mustelin, Elina, Nelonen, kanavapäällikkö, haastattelu 4.2.2014 Helsingissä.

Paunio, Matti, MTV, kotimaisten ohjelmien päällikkö, haastattelu 7.2.2014 Helsingissä.

Pääkkönen, Tarja, Shine Finland, managing director, 17.2.2014 Helsingissä.

Reijonen, Samu, Yle, tuottaja, haastattelu 28.1.2014 Tampereella.

Saaranluoma, Riku, Yle TV2, ohjelmapäällikkö, haastattelu 10.2.2014 Helsingissä.

Suominen, Olli, Nelonen, kotimaisten ohjelmien päällikkö, haastattelu 4.2.2014 Helsingissä.

Valtanen, Sari, MTV, vastaava tuottaja (kotimaiset ohjelmat), haastattelu 4.3.2014 Helsingissä.

Vermilä, Erika, FremantleMedia, toimitusjohtaja, haastattelu 4.2.2014 Helsingissä.

Väliahdet, Pentti, Yle TV1, ohjelmapäällikkö, haastattelu 12.2.2014 Helsingissä.

\section{Kirjallisuus}

Bennett, James \& Medrado, Andrea (2013). The business of multi-platform public service: Online and at a profit. Media International Australia 146, February, 103-113.

Beyer, Yngvil; Enli, Gunn Sara; Maas $\emptyset$, Art Johan \& Ytreberg, Espen (2007). Small Talk Makes a Big Difference; Recent Developments in Interactive, SMS-Based Television. Television Q New Media 8: 3, 213-234.

Bolin, Göran (2011). Value and the Media. Cultural Production and Consumption in Digital Markets. Ashgate.

Bordwell, David; Steiger Janet, \& Thompson, Kristin (1985). The Classical Hollywood Cinema: Film Style and Mode of Production to 1960. New York: Columbia University.

Debrett, Mary (2009). Riding the wave: Public service television in the multi-platform era. Media, Culture Q Society 31: 5, 807-827.

Deuze, Mark (2008). The professional identity of journalists in the context of convergence culture. Observatorio Journal 2: 4, 103-117.

Doyle, Gillian (2010). From Television to Multi-Platform. Less from More or More for Less? Convergence 16: 4, 1-19.

Enli, Gunn Sara (2008). Redefining Public Service Broadcasting: Multi-Platform Participation. Convergence 14: 1, 105-120.

Enli, Gunn Sara (2012). From parasocial interaction to social TV: Analysing the host-audience relationship in multi-platform productions. Northern Lights 10, 123-137.

Ihlabæk, Karoline Andrea; Syvertsen, Trine \& Ytreberg, Espen (2013). Keeping Them and Moving Them: TV Scheduling in the Phase of Channel and Platform Proliferation. Television and New Media, March 132013. Saatavilla: http://tvn.sagepub.com/content/early/2013/03/12/1527476413479676 (luettu 7.5.2015). 
Jenkins, Henry (2003). Transmedia storytelling. Technology Review, January 15, 2003. Saatavilla: http:// www.technologyreview.com/news/40176o/transmedia-storytelling/ (luettu 7.5.2015).

Jenkins, Henry (2006). Convergence Culture. Where Old and New Media Collide. New York: New York University Press.

Keinonen, Heidi (2011). Kamppailu yleistelevisiosta. TES-TV:n, Mainos-TV:n ja Tesvsion merkitykset suomalaisessa telvisiokulttuurissa 1956-1964. Tampere: TUP.

Klein-Shagrir, Oranit (2013). Barbed wire around glass walls: Making television production apparatus visible as a "para-interactive" strategy. Paperi IAMCR-konferenssissa Dublinissa 25--29.6.2013.

Klein-Shagrir, Oranit \& Keinonen, Heidi (2014). Public service television in a multi-platform environment: A comparative study in Finland and Israel. VIEW Journal of European Television History and Culture 3: 6, 14-23. Saatavilla: http://journal.euscreen.eu/index.php/view/article/view/JETHCo66/162 (luettu 7.5.2015).

Moilanen, Pentti \& Räihä, Pekka (2001). Merkitysrakenteiden tulkinta. Teoksessa: Aaltola, Juhani \& Valli, Raine (toim.). Ikkunoita tutkimusmetodeihin II. Näkökulmia aloittelevalle tutkijalle tutkimuksen teoreettisiin lähtökohtiin ja analyysimenetelmiin. Jyväskylä: PS Kustannus.

Newcomb, Horace \& Lotz, Amanda (2002). The production of media fiction. Teoksessa: Jensen, Klaus Bruhn (toim.). A Handbook of Media and Communication Research. Qualitative and Quantitative Methodologies. London: Routledge.

Roig, Antoni; San Cornelio, Gemma; Ardèvol, Elisenda; Alsina, Pau \& Pagès, Ruth (2009). Videogame as media practice: An exploration of the intersections between play and audiovisual culture. Convergence 15: 1, 89-103.

Roscoe, Jane (2004). Multi-platform event television: Reconceptualizing our relationship with television. The Communication Review 7: 4, 363-369.

Ross, Sharon Marie (2008). Beyond the Box: Television and the Internet. Malden: Blackwell

Ruoho, liris (2001). Utility Drama. Making of and Talking about the Serial Drama in Finland. Tampere: TUP.

Simons, Nele; Dhoest, Alexander \& Malliet, Steven (2012). Beyond the text: Producing cross- and transmedia fiction in Flanders. Northern Lights 10: 1, 25-40.

Scolari, Carlos Alberto (2009). Transmedia storytelling: Implicit consumers, narrative worlds, and branding in contemporary media production. International Journal of Communication 3, 586-606.

Spigel, Lynn \& Olsson, Jan (toim.) (2004). Television after TV - Essays on a Medium in Transition. Durham \& London: Duke University Press.

Turner, Graeme \& Tay, Jinna (toim.) (2009). Television Studies after TV. Understanding Television in the PostBroadcast Era. London: Routledge.

Van Dijck, Jose \& Poell, Thomas (2014). Making public television social? Public service broadcasting and the challenges of social media. Television and New Media, March 21, 2014. Saatavilla: http://tvn. sagepub.com/content/16/2/148.short?rss=1\&ssource=mfr (luettu 7.5.2015). 